\title{
Effects of Perceived Discrimination and Length of Residency on the Health of Foreign-Born Populations
}

\author{
Shauna K. Carlisle • Andrea L. Stone
}

Received: 12 September 2014 / Revised: 7 February 2015 / Accepted: 16 February 2015 / Published online: 12 March 2015

(C) W. Montague Cobb-NMA Health Institute 2015

\begin{abstract}
This study explores the relationship between chronic conditions, perceived discrimination, and length of residency among three racial groups of foreign-born respondents: Afro-Caribbean, Asian, and Latino Americans. Analysis utilized Collaborative Psychiatric Epidemiology Surveys (CPES) merged data from the National Latino and Asian American Study (NLAAS) and the National Survey of American Life (NSAL). Afro-Caribbean subgroups were more likely than Asian and Latino American subgroups to report perceived discrimination. Logistic regression analysis was conducted to determine which groups within the model were more likely to report chronic health conditions. Perceived discrimination was found to vary by race and was inversely associated with chronic respiratory conditions for Afro-Caribbeans. In general, years of US residency were associated with health across all chronic conditions where those in the USA longer were more likely to experience health-related problems. Perceived discrimination revealed mixed results.
\end{abstract}

Keywords Perceived discrimination $\cdot$ Chronic health . Afro-Caribbean · Ethnicity · Length of residency $\cdot$ Exposure

S. K. Carlisle $(\bowtie)$

School of Interdisciplinary Arts and Sciences, University of Washington Bothell, 18115 Campus Way NE, Box 358530 , Bothell, WA 98011-8246, USA

e-mail: ske9902@u.washington.edu

\section{A. L. Stone}

School of Nursing and Health Studies, University of Washington

Bothell, 18115 Campus Way NE, Box 358532,

Bothell, WA 98011-8246, USA

e-mail: astone@uwb.edu

\section{Introduction}

Experienced and perceived discrimination have negative effects on the physical health of racialized populations. Research to date has documented that across multiple indicators, discrimination is negatively linked to physical health $[12,13$, $15,26,27,29,32,52,54]$. Supporting the link between perceived discrimination and health is the theory "Fundamental Causes of Disease" $[22,33]$ which postulates that social conditions play a primary role in determining the health of individuals in the USA [42]. Specifically, discrimination is a form of psychosocial stress that has been linked to adverse health outcomes in the USA [53]. This relationship between racism as a fundamental cause of disease and chronic health has been found to exist among native-born respondents; however, research has not adequately explored the association between perceived discrimination and immigrant health while controlling for the potential impact of length of residency. Given these limitations, a systematic examination of the association between discrimination and health among foreign-born US populations is needed that goes a step further to consider reports of perceived discrimination and length of residency.

Perceived Discrimination and Length of Residency

Racial discrimination, as defined by the National Research Council, refers to the differential treatment on the basis of race, resulting in disadvantages to a racial group [38]. The literature on perceived discrimination postulates that even perceived unfair treatment attributed to one's racial or ethnic identity can result in an acute stress response [8, 34, 27, 43]. Though perceived discrimination has been criticized as being unverifiable [41] and lacking validity [51], it has become a common self-report measure for assessing discriminatory experiences [6, 30, 31, 35]. 
Recently, the analysis of perceived discrimination and health has been extended to foreign-born respondents [10, 14, 24, 39]. However, the analysis becomes complex when considering the role of length of residency. The health of foreign-born US residents has been found to be better than native born upon arrival [9] but declines over time in relation to their length of residency $[4,7,45,46,47,50]$. Stress related to the acculturation process is referred to as acculturative stress and has been reported to influence determinants of health such as depression [44, 49] and health behavior [1]. Some research has used length of residency as a proxy for acculturation $[20,28]$; however, length of residency is more likely than acculturation stresses to estimate exposure to perceived discrimination [56]. For example, Finch et al. [12] found that perceived discrimination was significantly associated with self-reported health status, including after controlling for the effects of acculturative stress. Likewise, in a study of Asian American mental health and language discrimination, Gee et al. [16] found a significant association between perceived discrimination and mental disorders, even after controlling for acculturative stress in their models. However, more research is needed to understand how perceived discrimination and length of residency interact across race. This study examines the impact of perceived discrimination and the impact of length of residency, along with various control variables, on the chronic health of foreign-born Asian American, Latino American, and Afro-Caribbean American respondents.

\section{Methods}

\section{Sample and Data Collection}

This study draws on two of three merged datasets from the 2001-2003 Collaborative Psychiatric Epidemiology Surveys (CPES): the National Latino and Asian American Study (NLAAS) and the National Survey of American Life (NSAL). These nationally representative surveys were compiled using a multi-stage area probability sample (For specific details of the NLAAS and NSAL study design and sample, see $[3,21$, 24]). The CPES is unique in that it contains similarities in sampling design, operationalization of measurements, and time frame in which the interviews took place across all surveys. Race group differences were adjusted using weighted age and gender estimates to match the census distributions for Asian and Latino sub-ethnic groups. This analysis included a total of 1,324 foreign-born Asian American (Vietnamese, Chinese, and Filipino), Latino American (Cuban, Puerto Rican, Mexican), and Afro-Caribbean Americans (Haitian, Jamaican, Trinidadian, and Tobagonian).

Weighted response rates for the NLAAS were $77.6 \%$ for Latinos and $69.3 \%$ for Asians, and for the NSAL, the rate was $75.7 \%$ for Afro-Caribbeans.
Measures

The NLASS and NLAS collect binary (yes/no) data on a number of health indicators, including allergies, asthma, hay fever, chronic lung conditions, back problems, headaches, arthritis, ulcers, heart trouble, stroke, heart disease, blood circulation, high blood pressure, heart attack, cancer, and diabetes. Replicating the methodology used by Gee et al. [15], the three primary outcome measures for this study were created by combining variables related to chronic cardiovascular disorders (heart attack, stroke, heart disease, high blood pressure, blood circulation), chronic respiratory disorders (hay fever, asthma, chronic lung disease), and chronic pain conditions (back pain, headache, arthritis, ulcer). Two other chronic conditions, diabetes and cancer, were included in the CPES surveys but were not analyzed for the present study.

The variable representing perceived discrimination was created from a 9-item scale based on research from the Detroit Area Study [55]. The scale included items assessing whether or not respondents experienced discriminatory acts, such as discourtesy, disrespect, and harassment, that they attribute to their racial/ethnic background. Respondents reported the frequency of perceived discrimination for each of the nine items on a 6-point scale ranging from "never" to having experienced harassment "almost every day." Respondents with fewer than six valid responses out of nine were omitted from the analyses, after which Proc mi procedures were conducted using SASS software to impute remaining missing values. Consistent with Gee et al. $[15,16]$, a continuous perceived discrimination measure was created by summing the nine variables and dividing by nine, resulting in a variable with a range of 1-6. This variable, which represented the dosage of perceived discrimination experienced, was then transformed into a final fourcategory perceived discrimination variable ranging from "noto-low" perceived discrimination ( $\operatorname{dosage}=0-1.5$ ), low perceived discrimination $($ dosage $=>1.5-2.5)$, moderate perceived discrimination (dosage $=>2.5-3.5$ ), and high discrimination (dosage $>3.5$ ). To support the unidimensional structure of our final dosage variable, factor analyses were conducted to assess shared variance between the nine discrimination items. The best fitting one-factor model produced an eigenvalue of 4.94 (factor loadings $=0.64-75$ ) with a Cronbach's alpha of 0.90. According to Comrey and Lee [11], factor loadings over 0.71 are considered "excellent." Finally, length of residency is a five-category item from the CPES data ranging from less than 5 years in residency, $5-10$ years in residency, $11-20$ years in residency, and greater than 20 years in residency. All regression models included the variables gender, age, education, income, and marital status to control for their potential influences on the chronic health profiles of foreign-born respondents (see tables for recoded demographic variable categories). 
Analysis Strategy

All analyses were conducted using SAS-callable SUDANN 9.0, which takes into account sample design effects and uses weights to adjust for demographic variables in the multi-stage stratification sampling, non-response rates, and post-stratification factors. The Weighted proc-cross tab procedure was used to compute descriptive statistics, including weighted percentage of reports of perceived discrimination and three measures of chronic health. To test the association between perceived discrimination, length of residency, and the potential interaction of these variables in relation to the three measures of chronic health by race, a step-wise approach to logistic regression was used starting with unadjusted models, then adjusting for gender, age, income, education, marital status, nativity, and ethnicity.

Unadjusted logistic regression models assessed associations between race and chronic cardiovascular, respiratory, and pain conditions. Unadjusted models were also run for years in the USA and chronic conditions and for perceived discrimination and chronic conditions. We then stratified by race to assess if, within racial categories, there is an association between perceived discrimination, years in USA, and chronic health conditions after controlling for demographic variables. The full adjusted model included the socioeconomic status (SES) variables for sex, age group, income level, years of education, and marital status, in addition to years in the USA and perceived discrimination.

\section{Results}

Table 1 contains demographic information for the three foreignborn race groups included in this study: Asian Americans, Latino Americans, and Afro-Caribbean Americans. Chisquare results reveal significant differences between Asian, Latino, and Afro-Caribbean immigrants in reports of cardiovascular conditions; Caribbeans had the highest reports of chronic cardiovascular conditions $(p<0.001)$, and Asians had the highest reports of chronic respiratory conditions $(p<0.0001)$. Chi-square revealed significant differences between groups in reporting perceived discrimination $(p<0.00001)$, indicating that there are variations by race in reports of experiences of discrimination; Afro-Caribbeans had the most frequent reports of discrimination-a few times a month. Interestingly, differences by length of residency were not significant.

Unadjusted and unstratified models for race and chronic conditions revealed that race was significantly associated with chronic cardiovascular and respiratory conditions (see Table 2: unadjusted results). Afro-Caribbeans were more likely than Latinos to report chronic cardiovascular (odds ratio $(\mathrm{OR})=$ $1.79)$ and respiratory conditions $(\mathrm{OR}=1.23)$, whereas Asian respondents were more likely than Latino or Afro-Caribbean Americans to report respiratory conditions $(\mathrm{OR}=2.27)$. When examining the relationship between years in the USA and chronic conditions, models reveal that those who have lived in the USA longer than 5 years were at increased risk of respiratory conditions. For cardio and pain conditions, only those who have lived in the USA for 20 years or more were at greater risk of cardiovascular $(\mathrm{OR}=3.62)$ and pain $(\mathrm{OR}=1.74)$ conditions. For respiratory conditions, there is greater risk with increased length of residency at all three lengths of residency periods $(\mathrm{OR}=2.05, \mathrm{OR}=1.86$, and $\mathrm{OR}=2.84$, respectively), indicating that immigrants' risk for respiratory conditions continues to increase the longer they live in the USA. Models examining the relationship between perceived discrimination and chronic conditions revealed no significant findings. However, marginal findings suggested that experiencing a moderate dose of perceived discrimination may be associated with an increased odds of cardiovascular conditions (OR $=1.43,95 \%$ confidence interval $(\mathrm{CI})[1: 00$ $2: 05], p=0.0504)$ and a decreased odds of experiencing respiratory conditions by about $30 \%(p=0.0731)$.

\section{Adjusted Models for Chronic Cardiovascular Conditions}

Tables 3, 4, and 5 report variables associated with chronic cardiovascular conditions by race adjusting for SES in model 1 ; years in the USA in model 2; perceived discrimination in model 3; and SES, years in USA, and perceived discrimination in model 4. Asian respondents with 13-15 years of education were less likely than other education groups to report cardiovascular conditions across all adjusted models $(\mathrm{OR}=$ $0.66, \mathrm{OR}=0.61, \mathrm{OR}=0.43$, and $\mathrm{OR}=0.38$, respectively). Those who were never married were also less likely than those who were or had been married to report chronic cardiovascular conditions across all adjusted models $(\mathrm{OR}=0.35, \mathrm{OR}=$ $0.38, \mathrm{OR}=0.36$, and $\mathrm{OR}=0.39$, respectively). Asian respondents who have lived in the USA for 20 or more years were more likely than other age groups to experience cardiovascular problems adjusting for SES and years of residency $(\mathrm{OR}=$ 2.42) and for SES, years of residency, and perceived discrimination $(\mathrm{OR}=2.96)$. This suggests that Asian respondents who have been in the USA longer are more likely to report cardiovascular problems when controlling for years residency or for years residency and perceived discrimination but not for perceived discrimination alone.

For Latino respondents, age was also strongly associated with cardiovascular problems such that each successive age group was more likely than the previous age group to report cardiovascular problems $(\mathrm{OR}=1.79, \mathrm{OR}=2.54$, and $\mathrm{OR}=3.29$, respectively). These age group associations remained significant in model $2(\mathrm{OR}=1.91, \mathrm{OR}=2.49, \mathrm{OR}=3.04)$ and persisted for the 35-49 age group $(\mathrm{OR}=1.97)$ and 50-64 age group $(\mathrm{OR}=2.48)$ when controlling for perceived discrimination in model 3. However, after controlling for SES and perceived discrimination, the difference for the $65+$ age group was no 
Table 1 Weighted sample characteristics of Asian, Latino, and Afro-Caribbean respondents

\begin{tabular}{|c|c|c|c|c|c|}
\hline Total sample & $\begin{array}{l}\text { Total } \\
\text { Sample } \\
N=3,579\end{array}$ & $\begin{array}{l}\text { Percentage } \\
\text { Asian } \\
\text { American } \\
n=1,324\end{array}$ & $\begin{array}{l}\text { Percentage } \\
\text { Latino } \\
\text { American } \\
n=1,205\end{array}$ & $\begin{array}{l}\text { Percentage } \\
\text { Caribbean } \\
\text { American } \\
n=1,050\end{array}$ & $\begin{array}{l}\text { Chi-squared } \\
p \text { value }\end{array}$ \\
\hline \multicolumn{6}{|l|}{ Demographic characteristics } \\
\hline \multicolumn{6}{|l|}{ Chronic health conditions } \\
\hline Chronic cardiovascular & & 22.18 & 17.39 & 27.4 & 0.001 \\
\hline Chronic respiratory & & 34.7 & 19.0 & 22.0 & $<0.0001$ \\
\hline Chronic pain & & 38.5 & 35.8 & 34.0 & 0.2486 \\
\hline Experienced discrimination & & & & & $<0.0001$ \\
\hline Never & & 54.6 & 54.5 & 32.0 & \\
\hline Once per year & & 31 & 31.4 & 34.8 & \\
\hline Few times per year & & 12.8 & 10.6 & 26.1 & \\
\hline Few times per month or more & & 1.6 & 3.5 & 7.0 & \\
\hline Years in the USA & & & & & 0.064 \\
\hline Less than 5 years & & 15.8 & 16.9 & 13.0 & \\
\hline $5-10$ years & & 18.1 & 15.6 & 14.4 & \\
\hline $11-20$ years & & 34.5 & 29.5 & 32.7 & \\
\hline More than 20 years & & 31.6 & 38.0 & 39.9 & \\
\hline Women & & 55.2 & 46.0 & 47.8 & 0.0017 \\
\hline Age & & & & & $<0.0001$ \\
\hline $18-34$ & & 34.6 & 51.8 & 46.2 & \\
\hline $35-49$ & & 35.6 & 26.9 & 28.3 & \\
\hline $50-64$ & & 21.2 & 14.8 & 14.9 & \\
\hline $65+$ & & 8.6 & 6.5 & 10.7 & \\
\hline Household income & & & & & $<0.0001$ \\
\hline Less than US\$20,000 & & 20.7 & 37.6 & 28.7 & \\
\hline US\$20,000-34,999 & & 11.4 & 21.7 & 29.4 & \\
\hline US\$35,000-49,999 & & 12.8 & 14.0 & 16.0 & \\
\hline US\$50,000-64,999 & & 11.3 & 9.8 & 10.8 & \\
\hline US $\$ 65,000$ or more & & 43.8 & 17.0 & 15.0 & \\
\hline Education & & & & & $<0.0001$ \\
\hline $0-11$ years & & 23.2 & 62.1 & 20.1 & \\
\hline 12 years & & 17.4 & 20.0 & 33.0 & \\
\hline $13-15$ years & & 23.0 & 10.7 & 25.1 & \\
\hline 16 years or more & & 36.4 & 7.1 & 21.8 & \\
\hline Marital status & & & & & $<0.0001$ \\
\hline Married/cohabitating & & 75.5 & 72.9 & 56.9 & \\
\hline Divorce/separated/widowed & & 9.3 & 11.9 & 20.1 & \\
\hline Never married & & 15.2 & 15.1 & 23.0 & \\
\hline
\end{tabular}

longer statistically significant. The association between age and cardiovascular conditions for the 50-64 age group and 65+ age group disappeared after controlling for SES, years of residency, and perceived discrimination in model 4. Finally, divorced Latinos were more likely than married Latinos to experience cardiovascular problems across all adjusted models $(\mathrm{OR}=2.37$, $\mathrm{OR}=1.74, \mathrm{OR}=2.90$, and $\mathrm{OR}=2.28$, respectively).

For Afro-Caribbean immigrants, income was not significant in the model until adjusting for SES, years of residency, and perceived discrimination, after which respondents earning US\$35,000-49,000 a year were less likely than other income groups to report chronic cardiovascular conditions $(\mathrm{OR}=$ 0.42). Further, Afro-Caribbean immigrants with 13-15 years of education were less likely than other residency year groups to report cardiovascular conditions $(\mathrm{OR}=0.29)$ after controlling for SES variables. These findings persisted after controlling for years of residency $(\mathrm{OR}=0.27), \mathrm{SES}$, and perceived discrimination $(\mathrm{OR}=0.37)$, and $\mathrm{SES}$, years of residency, and perceived discrimination in model $4(\mathrm{OR}=0.39)$. Never married Afro-Caribbeans were less likely to report cardiovascular conditions across all models $(\mathrm{OR}=0.24, \mathrm{OR}=0.28$, $\mathrm{OR}=0.16$, and $\mathrm{OR}=0.17$, respectively). 
Table 2 Unadjusted association between study variables and chronic health outcomes

\begin{tabular}{|c|c|c|c|c|c|c|c|c|c|}
\hline & \multicolumn{3}{|c|}{ Cardiovascular } & \multicolumn{3}{|c|}{ Respiratory } & \multicolumn{3}{|l|}{ Pain } \\
\hline & OR & OR $95 \% \mathrm{CI}$ & $p$ value & OR & OR $95 \% \mathrm{CI}$ & $p$ value & OR & OR $95 \% \mathrm{CI}$ & $p$ value \\
\hline \multicolumn{10}{|l|}{ Race } \\
\hline Latino (reference) & 1.00 & - & - & 1.00 & - & - & 1.00 & - & - \\
\hline Asian & 1.35 & $(0.98,1.88)$ & 0.675 & 2.27 & $(1.83,2.81)$ & $<0.0001$ & 1.12 & $(0.91,1.39)$ & 0.2830 \\
\hline Afro-Caribbean & 1.79 & $(1.42,2.27)$ & $<0.0001$ & 1.23 & $(1.01,1.50)$ & $<0.0001$ & 0.92 & $(0.71,1.19)$ & 0.5188 \\
\hline \multicolumn{10}{|l|}{ Years in the USA } \\
\hline$<5$ years & 1.00 & - & - & 1.00 & - & - & 1.00 & - & - \\
\hline $5-10$ years & 1.17 & $(0.71,1.91)$ & 0.5397 & 2.05 & $(1.16,3.64)$ & 0.0142 & 1.11 & $(0.77,1.60)$ & 0.5713 \\
\hline $11-20$ years & 1.12 & $(0.68,1.86)$ & 0.6542 & 1.86 & $(1.28,2.72)$ & 0.0015 & 0.99 & $(0.73,1.60)$ & 0.9739 \\
\hline $20<$ years & 3.62 & $(2.56,5.12)$ & $<0.0001$ & 2.84 & $(1.94,4.07)$ & $<0.0001$ & 1.74 & $(1.33,2.28)$ & 0.0001 \\
\hline \multicolumn{10}{|c|}{ Perceived discrimination } \\
\hline None & 1.00 & - & - & 1.00 & - & - & 1.00 & - & - \\
\hline Low dose & 0.85 & $(0.59,1.21)$ & 0.3631 & 0.85 & $(0.62,1.14)$ & 0.2738 & 0.89 & $(0.71,1.11)$ & 0.2829 \\
\hline Moderate dose & 1.43 & $(1.00,2.05)$ & 0.0504 & 0.69 & $(0.46,1.04)$ & 0.0731 & 1.31 & $(0.84,2.06)$ & 0.2325 \\
\hline High dose & 0.66 & $(0.27,1.59)$ & 0.3484 & 1.03 & $(0.46,2.31)$ & 0.9435 & 1.06 & $(0.61,1.87)$ & 0.8248 \\
\hline
\end{tabular}

Data in bold represents significant $p$ values at .05 or less

\section{Adjusted Model for Chronic Respiratory Conditions}

As reported in Table 4, Asian respondents in the 35-49 age group were at increased odds of respiratory problems adjusting for SES $(\mathrm{OR}=1.72)$. Findings for 35-49-year age groups stayed consistent after controlling for SES and years in the USA $(\mathrm{OR}=1.72)$, SES and perceived discrimination $(\mathrm{OR}=1.64)$, and SES and years in the USA plus perceived discrimination in model $4(\mathrm{OR}=1.62)$. The age group $65+$ also reported experiencing respiratory problems after controlling for SES (OR=1.99); however, this finding disappeared when adding years in the USA and perceived discrimination. When we control for perceived discrimination in model 4, Asian respondents who have lived in the USA for 5-10 years were more likely than other residency periods to experience respiratory problems $(\mathrm{OR}=2.50)$. Likewise, Asian respondents who have lived in the USA for 20 or more years were more likely than those in other age groups to report respiratory conditions $(\mathrm{OR}=2.67)$ after controlling for years of residency in model 2 and years of residency and perceived discrimination in model $4(\mathrm{OR}=2.76)$. Respondents 65 and over were more likely to report chronic respiratory conditions $(\mathrm{OR}=$ 1.99), but these findings disappeared after controlling for years of residency suggesting that residency may have more of an effect than perceived discrimination among Asian immigrants.

After controlling for SES variables, 35- to 49-year-old Latino respondents were more likely than 18- to 34-year-olds to experience respiratory conditions $(\mathrm{OR}=1.54)$. This finding remained true after controlling for perceived discrimination $(\mathrm{OR}=1.78)$. However, in the model with SES and years in the USA and in the full adjusted model, the association becomes not statistically significant, indicating a possible effect from years of US residency. Those with 13-15 years of education were more likely than other education level groups to experience respiratory problems $(\mathrm{OR}=1.76)$, even after controlling for years in the USA (OR=1.72), but not after controlling for perceived discrimination. Interestingly, when controlling for SES and perceived discrimination, the finding for the 13-15 years of education group disappeared, whereas 12 years of education became significant $(\mathrm{OR}=1.72)$. Latino respondents who lived in the USA for 20 or more years were more likely than recently arrived respondents to experience respiratory problems after controlling for SES and years of residency $(\mathrm{OR}=3.10)$ and again after controlling for SES, years of residency, and perceived discrimination $(\mathrm{OR}=3.73)$.

Similarly, Afro-Caribbean respondents with 13-15 years of education were more likely to experience respiratory problems in all four models $(\mathrm{OR}=5.52, \mathrm{OR}=5.22, \mathrm{OR}=4.85$, and $\mathrm{OR}=$ 4.43 , respectively). Age was not associated with respiratory problems among Afro-Caribbeans until we controlled for perceived discrimination in model 3 , where the 65 years and over age group was less likely than other age groups to experience respiratory problems $(\mathrm{OR}=0.31)$. This finding persisted even after controlling for years of residency and perceived discrimination in model $4(\mathrm{OR}=0.29)$. Afro-Caribbean respondents were the only race group that reported significant associations between perceived discrimination and respiratory conditions. Respondents who reported a low or moderate dose of perceived discrimination were less likely to experience respiratory problems than those who reported no discrimination in model $3(\mathrm{OR}=0.44, \mathrm{OR}=0.36$, respectively). This finding 
Table 3 Variables associated with chronic cardiovascular conditions: adjusted models

\begin{tabular}{|c|c|c|c|c|c|c|c|c|c|c|c|c|}
\hline & \multicolumn{3}{|l|}{ Model 1 (SES) } & \multicolumn{3}{|c|}{$\begin{array}{l}\text { Model } 2 \text { (model } 1+\text { years } \\
\text { in the USA) }\end{array}$} & \multicolumn{3}{|c|}{$\begin{array}{l}\text { Model } 3 \text { (model } 1+\text { perceived } \\
\text { discrimination }\end{array}$} & \multicolumn{3}{|c|}{$\begin{array}{l}\text { Model } 4 \text { (SES, USA + } \\
\text { perceived discrimination) }\end{array}$} \\
\hline & Population & OR & $p$ value & Population & OR & $p$ value & Population & OR & $p$ value & Population & OR & $p$ value \\
\hline \multicolumn{13}{|c|}{ Perceived discrimination $($ none $=$ reference $)$} \\
\hline \multicolumn{13}{|l|}{ Low dose } \\
\hline \multicolumn{13}{|l|}{ Moderate dose } \\
\hline \multicolumn{13}{|l|}{ High dose } \\
\hline \multicolumn{13}{|c|}{ Years in the USA $(<5$ years $=$ reference $)$} \\
\hline $5-10$ years & & & & & & & & & & Latino & 0.38 & 0.0294 \\
\hline \multicolumn{13}{|l|}{$11-20$ years } \\
\hline \multirow[t]{2}{*}{$20<$ years } & & & & Asian & 2.42 & 0.0047 & & & & Asian & 2.96 & 0.0042 \\
\hline & & & & Latino & 2.16 & 0.0210 & & & & & & \\
\hline \multicolumn{13}{|l|}{ Sex $($ male $=$ reference $)$} \\
\hline \multicolumn{13}{|l|}{ Female } \\
\hline \multicolumn{13}{|c|}{ Age (18-34 = reference) } \\
\hline $35-49$ & Latino & 1.79 & 0.0258 & Latino & 1.91 & 0.0084 & Latino & 1.97 & 0.0314 & Latino & 1.99 & 0.0258 \\
\hline $50-64$ & Latino & 2.54 & 0.0196 & Latino & 2.49 & 0.0178 & Latino & 2.48 & 0.0438 & & & \\
\hline 65 and over & Latino & 3.29 & 0.0005 & Latino & 3.04 & 0.0004 & & & & Latino & 2.10 & 0.1069 \\
\hline \multicolumn{13}{|c|}{ Income $(<$ US $\$ 20,000=$ reference $)$} \\
\hline \multicolumn{13}{|l|}{ US\$20,000-34,999 } \\
\hline US $\$ 35,000-49,999$ & & & & & & & & & & Afro-Caribbean & 0.42 & 0.0171 \\
\hline \multicolumn{13}{|l|}{ US\$50,000-64,999 } \\
\hline \multicolumn{13}{|l|}{ US\$65,000 and over } \\
\hline \multicolumn{13}{|c|}{ Education $(0-11$ years $=$ reference $)$} \\
\hline \multicolumn{13}{|l|}{12 years } \\
\hline $13-15$ years & Asian & 0.66 & 0.0390 & Asian & 0.61 & 0.0303 & Asian & 0.43 & $<0.0001$ & Asian & 0.38 & $<0.0001$ \\
\hline 16 years and over & Afro-Caribbean & 0.29 & 0.0397 & Afro-Caribbean & 0.27 & 0.0321 & Afro-Caribbean & 0.37 & 0.0291 & Afro-Caribbean & 0.39 & 0.0491 \\
\hline \multicolumn{13}{|c|}{ Marital status $($ married/cohabitating $=$ reference $)$} \\
\hline \multirow[t]{2}{*}{ Divorced/separated } & Asian & 1.57 & 0.0375 & & & & & & & & & \\
\hline & Latino & 2.37 & 0.0018 & Latino & 1.74 & 0.0155 & Latino & 2.90 & 0.0013 & Latino & 2.28 & 0.0088 \\
\hline \multirow[t]{2}{*}{ Never married } & Asian & 0.35 & 0.0059 & Asian & 0.38 & 0.0107 & Asian & 0.36 & 0.0099 & Asian & 0.39 & 0.0204 \\
\hline & Afro-Caribbean & 0.24 & $<0.0001$ & Afro-Caribbean & 0.28 & $<0.0001$ & Afro-Caribbean & 0.16 & $<0.0001$ & Afro-Caribbean & 0.17 & $<0.0001$ \\
\hline
\end{tabular}

persisted for both groups who experienced low and moderate dosages of discrimination in the full model that adjusted for SES, years in the USA, and perceived discrimination $(\mathrm{OR}=$ 0.36 and $\mathrm{OR}=0.37$, respectively). Finally, Afro-Caribbeans who have lived in the USA for 11 to 20 years are more likely than other residency periods to experience respiratory conditions in the full adjusted model $(\mathrm{OR}=2.26)$. It seems AfroCaribbean immigrants were more likely to report discrimination but unlikely to report direct effects on respiratory health. No significant findings emerged for marital status and respiratory conditions.

\section{Adjusted Models for Chronic Pain Conditions}

Table 5 reports the logistic regression results for variables associated with chronic pain conditions. Results revealed that perceived discrimination was not associated with chronic pain conditions for any race group. However, for those never married, Asian respondents were less likely than Latinos or AfroCaribbeans to experience chronic pain across all adjusted models $(\mathrm{OR}=0.49, \mathrm{OR}=0.50, \mathrm{OR}=0.43$, and $\mathrm{OR}=0.44$, respectively). Interestingly, gender associations emerged for all groups. Women were more likely than men to experience chronic pain across all adjusted models $(\mathrm{OR}=1.60, \mathrm{OR}=$ $1.62, \mathrm{OR}=1.85, \mathrm{OR}=1.85$ ). Significant gender findings were reported for Latino respondents; females were more likely than men to report chronic pain conditions across all adjusted models $(\mathrm{OR}=2.60, \mathrm{OR}=2.70, \mathrm{OR}=2.51$, and $\mathrm{OR}=2.58$, respectively). Further, Latinos in the 50-64 age group were also more likely than those in other age groups to report chronic pain conditions after controlling for SES $(\mathrm{OR}=1.66)$. This finding disappeared in model 2 and reappeared in model 3, 
Table 4 Variables associated with chronic respiratory conditions: adjusted models

\begin{tabular}{|c|c|c|c|c|c|c|c|c|c|c|c|c|}
\hline & \multicolumn{3}{|l|}{ Model 1 (SES) } & \multicolumn{3}{|c|}{$\begin{array}{l}\text { Model } 2 \text { (model } 1+\text { years in } \\
\text { the USA) }\end{array}$} & \multicolumn{3}{|c|}{$\begin{array}{l}\text { Model } 3 \text { (model } 1+\text { perceived } \\
\text { discrimination) }\end{array}$} & \multicolumn{3}{|c|}{$\begin{array}{l}\text { Model } 4 \text { (SES, USA + } \\
\text { perceived discrimination) }\end{array}$} \\
\hline & Population & OR & $p$ value & Population & OR & $p$ value & Population & OR & $p$ value & Population & OR & $p$ value \\
\hline \multicolumn{13}{|c|}{ Perceived discrimination $($ none $=$ reference $)$} \\
\hline \multicolumn{4}{|l|}{ Low dose } & & & & Afro-Caribbean & 0.44 & 0.0416 & Afro-Caribbean & 0.36 & 0.0081 \\
\hline \multicolumn{4}{|l|}{ Moderate dose } & & & & Afro-Caribbean & 0.36 & 0.0223 & Afro-Caribbean & 0.37 & 0.0158 \\
\hline \multicolumn{13}{|l|}{ High dose } \\
\hline \multicolumn{13}{|c|}{ Years in the USA $(<5$ years $=$ reference $)$} \\
\hline \multicolumn{4}{|l|}{$5-10$ years } & & & & & & & Asian & 2.50 & 0.0296 \\
\hline \multicolumn{4}{|l|}{$11-20$ years } & & & & & & & Afro-Caribbean & 2.26 & 0.0325 \\
\hline \multirow[t]{2}{*}{$20<$ years } & & & & Asian & 2.67 & 0.0006 & & & & Asian & 2.76 & 0.0053 \\
\hline & & & & Latino & 3.10 & 0.0064 & & & & Latino & 3.73 & 0.0035 \\
\hline \multicolumn{13}{|l|}{ Sex $($ male $=$ reference $)$} \\
\hline \multicolumn{13}{|l|}{ Female } \\
\hline \multicolumn{13}{|c|}{ Age $(18-34=$ reference $)$} \\
\hline \multirow[t]{2}{*}{$35-49$} & Asian & 1.72 & 0.0033 & Asian & 1.72 & 0.0026 & Asian & 1.64 & 0.0413 & Asian & 1.62 & 0.0485 \\
\hline & Latino & 1.54 & 0.0185 & & & & Latino & 1.78 & 0.0227 & & & \\
\hline \multicolumn{13}{|l|}{$50-64$} \\
\hline 65 and over & Asian & 1.99 & 0.0226 & & & & Afro-Caribbean & 0.31 & 0.0432 & Afro-Caribbean & 0.29 & 0.0451 \\
\hline \multicolumn{13}{|c|}{ Income $(<\mathrm{US} \$ 20,000=$ reference $)$} \\
\hline \multicolumn{13}{|l|}{ US\$20,000-34,999 } \\
\hline \multicolumn{13}{|l|}{ US\$35,000-49,999 } \\
\hline US\$50,000-64,999 & Latino & 2.14 & 0.0273 & & & & & & & & & \\
\hline \multicolumn{13}{|l|}{ US\$65,000 and over } \\
\hline \multicolumn{13}{|c|}{ Education $(0-11$ years $=$ reference $)$} \\
\hline 12 years & Afro-Caribbean & 2.05 & 0.0400 & Afro-Caribbean & 2.21 & 0.040 & Latino & 1.72 & 0.0458 & & & \\
\hline $13-15$ years & Latino & 1.76 & 0.0092 & Latino & 1.72 & 0.0160 & & & & & & \\
\hline 16 years and over & Afro-Caribbean & 5.52 & $<0.0001$ & Afro-Caribbean & 5.22 & $<0.0001$ & Afro-Caribbean & 4.85 & 0.0045 & Afro-Caribbean & 4.43 & 0.0380 \\
\hline \multicolumn{13}{|c|}{ Marital status (married/cohabitating $=$ reference $)$} \\
\hline \multicolumn{13}{|l|}{ Divorced/separated } \\
\hline Never married & & & & & & & & & & & & \\
\hline
\end{tabular}

when controlling for perceived discrimination $(\mathrm{OR}=2.09)$. Divorced/separated Latino respondents were more likely than never married respondents to report pain conditions, when controlling for SES $(\mathrm{OR}=2.02)$, SES and years in the USA $(\mathrm{OR}=1.63)$, and SES and perceived discrimination $(\mathrm{OR}=$ 2.02), but this difference did not remain in the fully adjusted model. Finally, Afro-Caribbean respondents who have been in the USA for 5 to 10 years are more likely than any other length of residency periods to experience pain but only in the fully adjusted model $(\mathrm{OR}=1.94)$. Similar to Asians and Latinos, Afro-Caribbean women were more likely to report chronic pain after controlling for SES $(\mathrm{OR}=1.85)$, SES and years in the USA $(\mathrm{OR}=1.81)$, SES and perceived discrimination $(\mathrm{OR}=1.78)$, and SES, years of residency, and perceived discrimination $(\mathrm{OR}=1.67)$. Afro-Caribbeans who earned US $\$ 35$, 000-49,000 a year were more likely to experience pain in model $1(\mathrm{OR}=2.64)$, model $2(\mathrm{OR}=2.67)$, and model 3
$(\mathrm{OR}=1.99)$. However, this effect became insignificant in the fully adjusted model when controlling for years of residency and perceived discrimination. Finally, Afro-Caribbeans who made US $\$ 65,000$ or more per year were more likely to experience pain after controlling for SES and years residency $(\mathrm{OR}=1.90)$ and after adding perceived discrimination to the model $(\mathrm{OR}=2.13)$.

\section{Discussion}

The purpose of this study was to examine the relationship between chronic cardiovascular, respiratory, and pain conditions and race, perceived discrimination, and length of residency across a diverse population of foreign-born Asian American, Latino American, and Afro-Caribbean Americans. Utilizing two linked datasets from the CPES, we 
Table 5 Variables associated with chronic pain conditions: adjusted models

\begin{tabular}{|c|c|c|c|c|c|c|c|c|c|c|c|c|}
\hline & \multicolumn{3}{|l|}{ Model 1 (SES) } & \multicolumn{3}{|c|}{$\begin{array}{l}\text { Model } 2 \text { (model } 1+\text { years in } \\
\text { the USA) }\end{array}$} & \multicolumn{3}{|c|}{$\begin{array}{l}\text { Model } 3 \text { (model } 1+\text { perceived } \\
\text { discrimination) }\end{array}$} & \multicolumn{3}{|c|}{$\begin{array}{l}\text { Model } 4 \text { (SES, USA + } \\
\text { perceived discrimination) }\end{array}$} \\
\hline & Population & OR & $p$ value & Population & OR & $p$ value & Population & OR & $p$ value & Population & OR & $p$ value \\
\hline \multicolumn{13}{|c|}{ Perceived discrimination $($ none $=$ reference $)$} \\
\hline \multicolumn{13}{|l|}{ Low dose } \\
\hline \multicolumn{13}{|l|}{ Moderate dose } \\
\hline \multicolumn{13}{|l|}{ High dose } \\
\hline \multicolumn{13}{|c|}{ Years in the USA $(<5$ years $=$ reference $)$} \\
\hline $5-10$ years & & & & & & & & & & Afro-Caribbean & 1.94 & 0.0472 \\
\hline \multicolumn{13}{|l|}{$11-20$ years } \\
\hline $20<$ years & & & & Latino & 2.19 & 0.0110 & & & & Latino & 2.47 & 0.0143 \\
\hline \multicolumn{13}{|l|}{ Sex $($ male $=$ reference $)$} \\
\hline \multirow[t]{3}{*}{ Female } & Asian & 1.60 & 0.0012 & Asian & 1.62 & 0.0015 & Asian & 1.85 & $<0.0001$ & Asian & 1.85 & $<0.0001$ \\
\hline & Latino & 2.60 & $<0.0001$ & Latino & 2.70 & $<0.0001$ & Latino & 2.51 & $<0.0001$ & Latino & 2.58 & 0.0002 \\
\hline & Afro-Caribbean & 1.85 & 0.0106 & Afro-Caribbean & 1.81 & 0.0200 & Afro-Caribbean & 1.78 & 0.0358 & Afro-Caribbean & 1.67 & 0.0452 \\
\hline \multicolumn{13}{|c|}{ Age $(18-34=$ reference $)$} \\
\hline \multicolumn{13}{|l|}{$35-49$} \\
\hline $50-64$ & Latino & 1.66 & 0.0257 & & & & Latino & 2.09 & 0.0306 & & & \\
\hline \multicolumn{13}{|l|}{65 and over } \\
\hline \multicolumn{13}{|c|}{ Income $(<$ US $\$ 20,000=$ reference $)$} \\
\hline \multicolumn{13}{|l|}{ US\$20,000-34,999 } \\
\hline US\$35,000-49,999 & Afro-Caribbean & 2.64 & 0.0013 & Afro-Caribbean & 2.67 & 0.0019 & Afro-Caribbean & 1.99 & 0.0435 & & & \\
\hline \multicolumn{13}{|l|}{ US\$50,000-64,999 } \\
\hline US $\$ 65,000$ and over & & & & & & & Afro-Caribbean & 1.90 & 0.0384 & Afro-Caribbean & 2.13 & 0.0305 \\
\hline \multicolumn{13}{|c|}{ Education $(0-11$ years $=$ reference $)$} \\
\hline \multicolumn{13}{|l|}{12 years } \\
\hline \multicolumn{13}{|l|}{$13-15$ years } \\
\hline \multicolumn{13}{|l|}{16 years and over } \\
\hline \multicolumn{13}{|c|}{ Marital status (married/cohabitating $=$ reference) } \\
\hline Divorced/separated & Latino & 2.02 & $<0.0001$ & Latino & 1.63 & 0.0045 & Latino & 2.02 & 0.0148 & & & \\
\hline Never married & Asian & 0.49 & 0.0001 & Asian & 0.50 & 0.0002 & Asian & 0.43 & 0.0012 & Asian & 0.44 & 0.0025 \\
\hline
\end{tabular}

systematically analyzed the interrelationship between race, length of residency, and perceived discrimination, controlling for gender, age, income, education, and marital status. Results reveal that even among foreign-born respondents, there are variations in reports of perceived discrimination. However, unlike research on native-born respondents [5], reports of chronic conditions seem to be less linked to reports of perceived discrimination and more linked to a combination of perceived discrimination and length of residency. It suggests that among immigrants, the fundamental causes of disease theory as it relates to perceived discrimination may intersect with length of residency in that upon arrival perceived discrimination does not pose as great a threat but overtime its influence on health becomes much stronger as one resides in the USA longer. However, given the cross-sectional nature of the data, these findings need to be further investigated among longitudinal data.

\section{SES, Length of Residency, and Perceived Discrimination}

Afro-Caribbean respondents in this analysis were more likely to report chronic cardiovascular conditions than were Asian and Latino respondents. Interestingly, living in the USA for 20 years or longer was associated with a greater likelihood of reporting cardiovascular, respiratory, and pain conditions for Latino respondents and cardiovascular and respiratory conditions for Asian respondents with no significant associations for Afro-Caribbeans. Perceived discrimination alone was not associated with any chronic conditions among Latino and Asian Americans and only moderately and inversely associated with chronic respiratory conditions for Afro-Caribbean respondents. Their unique patterns of health, which are not clearly related to their high reports of perceived discrimination, may suggest possible buffering effects unaccounted for by this study, such as ethnic identification [36]. Further, 
overall these findings suggest that among immigrants, just as among native-born citizens, perceived discrimination may pose a greater threat to their health the longer they reside in the USA. This would be consistent with proposed relationships between transnationalism and ethnic identity [37].

\section{Conclusion}

Study findings suggest that to understand immigrant health, it may be important to take into consideration both the effects of length of residency and extent of perceived discrimination. This may be particularly true for Latino and Asian residents who experience increased chronic health problems the longer they reside in the USA. Afro-Caribbean respondents have a unique health profile which seems to coincide with reports of increased perceived discrimination; however, the effects of perceived discrimination on health appear limited.

While the study results are intriguing, they should be interpreted in light of several study limitations. First, the cross-sectional design of the CPES data limits our ability to study temporal ordering of the primary study variables. Importantly, further investigation is needed to capture temporal order as it relates to perceived discrimination and length of residency. One area that may provide theoretical grounds for further investigation among foreign-born populations is the "weathering hypothesis" [14]. The "weathering hypothesis," proposed by Geronimus [18], postulates that as cumulative disadvantage increases with experienced and perceived discrimination, health declines. Further, over time, these cumulative experiences have a negative influence on the health outcomes of racialized groups (1996). For example, studies have found that long-term social and economic stress is associated with chronic illness among African American women and that age is a primary factor for determining the amount of "weathering" that an individual may experience $[18,17,19]$. This age effect may provide insight into the relationship between length of residency and perceived discrimination given that foreign-born respondent's time of exposure to perceived discrimination would take place starting with arrival in the USA and continuing thereafter. Therefore, length of residency may be an equivalent to the measure of age in weathering [14]. Given the findings related to the weathering hypothesis among US-born citizens, if weathering is indeed a product of long-term exposure to discrimination, then the observed relationship between length of residency and perceived discrimination among foreign-born respondents in this current study may suggest similar weathering patterns. This would have significant implications for minority health in the USA if foreign-born residents with otherwise healthy profiles would experience declines in health similar to their nativeborn counterparts. Finally, given that immigrants are historically removed from social, historical experiences in the USA, an examination of weathering among immigrants could lead to a more parsimonious model measuring discrimination and health among racial immigrant subgroups.

Second, this study relies on self-reported reported measures of health rather than clinical diagnoses. However, it is important to note that researchers frequently rely on such measures, and some have successfully tested the validity of self-reports for experienced and perceived discrimination $[27,30]$ and for health conditions [23].

Third, in this study, we did not control for language barriers, which have previously been found to be associated with problems in self-reported health conditions [25], specifically among Asian Americans [56]. Additionally, variables such as selection bias [2], geographic location [48], and ethnic enclaves [40] are also factors associated with immigrant health. However, given the threat of over-parameterization in the statistical models, this study limited the covariates to those specific to the study questions.

Finally, we attempted to run an interaction term between years in USA and perceived discrimination; however, because so few people were in the most severe dosage of perceived discrimination group, cell sizes were inadequate to produce stable models.

Despite these limitations, the results of this study provide insight into the associations between perceived discrimination and length of residency in relation to the health of these foreign-born Americans. Findings suggest that future research and interventions aiming to lower the risk of chronic health declines among newly arriving populations may benefit from considering the unique profiles that lead to these declines.

Acknowledgment We thank Dr. David Takeuchi for providing access to the CPES. Partial support for this research came from a Eunice Kennedy Shriver National Institute of Child Health and Human Development research infrastructure grant, R24 HD042828, to the Center for Studies in Demography \& Ecology at the University of Washington.

Conflict of Interest The authors, Shauna K. Carlisle and Andrea L. Stone, declare that they have no conflict of interest. No animal or human studies were carried out by the authors for this article.

\section{References}

1. Abraido-Lanza AF, Chao MT, Gates CY. Acculturation and cancer screening among Latinos: results from the national health interview survey. Ann Behav Med. 2005;29:22-8.

2. Abraido-Lanza A, Dohrenwend B, Ng-Mak D, Turner J. The Latino mortality paradox: a test of the "salmon bias". Am J Public Health. 1999;89(10):1543-8. doi:10.2105/AJPH.89.10.1543.

3. Alegria M, Takeuchi D, Canino G, Duan N, Shrout P, Meng X, et al. Considering context, space and culture: the National Latino and Asian American Study. International Journal of Methods in Psychiatric Research. 2004;13(4):208-20. 
4. Antecol H, Bedard K. Unhealthy assimilation: why do immigrants converge to American health status levels? Demography. 2006;43(2): 337-60.

5. Brondolo E, Hausmann LR, Jhalani J, Pencille M, Atencio-Bacayon J, Kumar A, Schwartz J. Dimensions of perceived racism and selfreported health: examination of racial/ethnic differences and potential mediators. Ann Behav Med. 2011;42(1), 14-28. doi: 10.1007/ s12160-0119265-1.

6. Brondolo E, Kelly KP, Coakley V, Gordon T, Thompson S, Levy E. The perceived ethnic discrimination questionnaire: development and preliminary validation of a community version. J Appl Soc Psychol. 2005;35(2):335-65.

7. Buckley AJ, Sakamoto A. Duration or disadvantage? Exploring nativity, ethnicity, and health in midlife. J Gerontol B Psychol Sci Soc Sci. 2001;56(5):S275-84.

8. Cardova D. Intergroup and within-group perceived discrimination among U.S. born and foreign-born Latino youth. Hisp J Behav Sci. 2010;32(2):259-74.

9. Carlisle SK. Nativity differences in chronic health conditions between nationally representative samples of Asian American, Latino American, and Afro-Caribbean American respondents. J Immigr Minor Health. 2012;14(6):903-11. doi:10.1007/s10903-012-9606-6.

10. Carlisle SK. Perceived discrimination and chronic health in adults from nine ethnic sub-groups in the USA. Ethn Health. 2014;12:1-18.

11. Comrey A, Lee H. A first course in factor analysis. 2nd ed. Hillsdale: Lawrence Erlbaum; 1992.

12. Finch BK, Hummer RA, Kolody B, Vega WA. The role of discrimination and acculturative stress in the physical health of MexicanOrigin adults. Hisp J Behav Sci. 2001;23(4):399-429.

13. Flores E, Tschann J, Dimas J, Bachen E, Pasch L, de Groat C. Perceived discrimination, perceived stress, and mental and physical health among Mexican-Origin adults. Hisp J Behav Sci. 2008;30(4): 401-24.

14. Gee G, Ryan A, Laflamme D, Holt J. Self-reported discrimination and mental health status among African descendants, Mexican Americans, and other Latinos in the New Hampshire REACH 2010 initiative: the added dimension of immigration. Am J Public Health. 2006;96(10):1821-8.

15. Gee G, Spencer MS, Chen J, Takeuchi D. A nationwide study of discrimination and chronic health conditions among Asian Americans. Am J Public Health. 2007;97:1275-82. doi:10.215/ AJPH.2006.091827.

16. Gee G, Spencer MS, Chen J, Yip T, Takeuchi DT. The association between self-reported racial discrimination and 12-month DSM-IV mental disorders among Asian Americans nationwide. Soc Sci Med. 2007;64(10):1984-96.

17. Geronimus A. Understanding and eliminating racial inequalities in women's health in the United States: the role of the weathering conceptual framework. J Am Med Women's Assoc. 2001;56(4):133-6.

18. Geronimus AT. Black/White differences in the relationship of maternal age to birthweight: a population-based test of the weathering hypothesis. Social Sci Med. 1996;42:589-97.

19. Geronimus AT, Hicken M, Keene D, Bound J. "Weathering" and age patterns of allostatic load scores among blacks and whites in the United States. Am J Public Health. 2006;96:826-33.

20. Gfroerer JC, Tan LT. Substance use among foreign-boron youths in the United States: does the length of residence matter? Am J Public Health. 2003;93(11):1892-5.

21. Heeringa SF, Wager J, Torres M, Duan N, Adams T, Berglund P. Sample designs and sampling methods for the Collaborative Psychiatric Epidemiology Studies (CPES). Int J Methods Psychiatr Res. 2004;13:221-40.

22. House J, Kessler R. Age, socioeconomic status, and health. Milbank Quarterly. 1990;68:383-411.
23. Idler E, Benyamini Y. Self-rated health and mortality: a review of twenty-seven community studies. J Health Soc Behav. 1997;38:2137.

24. Jackson JS, Torres M, Caldwell CH, Neighbors HW, Nesse R, Taylor $\mathrm{R}$, et al. The National Survey of American Life: a study of racial, ethnic, and cultural influences on mental disorders and mental health. Int J Methods Psychiatric Res. 2004;13(4):196-207.

25. Kandula N, Lauderdale D, Baker D. Differences in self-reported health among Asians, Latinos, and non-Hispanic Whites: the role of language and nativity. Ann Epidemiol. 2007;17(3):191-8.

26. Karlsen S, Nazroo J. Relation between racial discrimination, social class, and health among ethnic minority groups. Am J Public Health. 2002;92(4):624-31.

27. Kessler RC, Michelson KD, Williams DR. The prevalence, distribution and mental health correlates of perceived discrimination in the United States. Am J Prev Med. 1999;9:82-122.

28. Koya DL, Egede LE. Association between length of residence and cardiovascular disease risk factors among an ethnically diverse group of United States immigrants. J Gen Intern Med. 2007;22(6):841-6.

29. Krieger N, Sidney S. Racial discrimination and blood pressure: the CARDIA study of young black and white adults. Am J Public Health. 1996;86(10):1370-8.

30. Krieger N, Smith K, Naishadham D, Harman C, Barbeau E. Experiences of discrimination: validity and reliability of a selfreport measure for population health research on racism and health. Soc Sci Med. 2005;61:1576-96.

31. Landrine H, Klonoff EA. The schedule of racist events: a measure of racial discrimination and a study of its negative physical and mental health consequences. J Black Psychol. 1996;22(2):144-68.

32. Lewis TT, Everson-Rose S, Powell L, Matthews K, Brown C, Karavolos K, et al. Chronic exposure to everyday discrimination and coronary artery calcification in African-American women: the SWAN heart study. Psychosom Med. 2006;68:362-8.

33. Link B, Phelan J. Social conditions as fundamental causes of disease. Journal of Health and Social Behavior. 1995;35:80-94. extra issue.

34. Mays V, Cochran S, Barnes N. Race, race-based discrimination, and health outcomes among African Americans. Annu Rev Psychol. 2007;58:201-25.

35. McNeilly MD, Anderson NB, Armstead CA, Clark R, Corbett M, Robinson EL, et al. The perceived racism scale: a multidimensional assessment of the experience of white racism among African Americans. Ethnicity Dis. 1996;6(1-2):154-66.

36. Mossakowski KN. Coping with perceived discrimination: does ethnic identity protect mental health? J Health Soc Behav. 2003;44: 318-31.

37. Murphy E, Mahalingam R. Transnational ties and mental health of Caribbean immigrants. J Immigr Health. 2004;6(4):1573-4045.

38. National Research Council of the Academies. Measuring racial discrimination. Washington, DC: The National Academies Press; 2004.

39. Noh S, Kaspar V, Wickrama KAS. Overt and subtle racial discrimination and mental health: preliminary findings for Korean immigrants. Am J Public Health. 2007;97(7):1269-74.

40. Osypuk T, Roux A, Hadley C, Kandula N. Are immigrant enclaves healthy places to live? The multi-ethnic study of atherosclerosis. Soc Sci Med. 2009;69(1):110-20.

41. Pascoe E, Richman L. Perceived discrimination and health: a metaanalytic review. Psychol Bull. 2009;135(4):531-54.

42. Phelan J, Link B. Social conditions as fundamental causes of health inequalities: theory, evidence, and policy implications. J Health Soc Behav. 2010;51:S28-40. doi:10.1177/0022146510383498.

43. Schmitt MT, Branscombe NR. The meaning of consequences of perceived discrimination in disadvantaged and privileged social groups. Eur Rev Soc Psychol. 2002;12:167-99.

44. Shen BJ, Takeuchi DT. A structural model of acculturation and mental health status among Chinese Americans. Am J Community Psychol. 2001;29(3):387. 
45. Singh G, Miller B. Health, life expectancy, and mortality patterns among immigrant populations in the United States. Can J Publ Health. 2004;95(3), I-14-21.

46. Singh GK, Siahpush M. Ethnic-immigrant differentials in health behaviors, morbidity, and cause-specific mortality in the United States: an analysis of two national data bases. Hum Biol. 2002; 74(1):83-109.

47. Stephen EH, Foote K, Hendershot GE, Schoenborn C. Health of the foreign-born population: United States, 1989-90. Adv Data Vital Health Stat. 1994 No. 241. Hyattsville, Maryland: U.S. Department of Health and Human Services Public Health Service, Centers for Disease Control and Prevention, National Center for Health Statistics.

48. Subramanian S, Kawachi I, Kennedy B. Does the state you live in make a difference? Multilevel analysis of self-rated health in the US. Soc Sci Med. 2001;53(1):9-19. doi:10. 1016/S0277-9536(00)00309-9.

49. Takeuchi DT, Chun C, Gong F, Shen H. Cultural expressions of distress. Health: Interdisciplinary J Social Study Health Illness Med. 2002;6(2):221-35.
50. Uretsky M, Mathiesen S. The effects of years lived in the United States on the general health status of California's foreign-born populations. J Immigr Minor Health. 2007;9(2):125-36.

51. Utsey SO. Assessing the stressful effects of racism: a review of instrumentation. J Black Psychol. 1998;24:269-88.

52. Williams D. Race, socioeconomic status, and health the added effects of racism and discrimination. Ann N Y Acad Sci. 2006;896:173-88.

53. Williams DR, Mohammed S. Discrimination and racial disparities in health: evidence and needed research. J Behav Med. 2009;32(1):137. doi:10.1007/s10865-008-9185-0.

54. Williams DR, Neighbors HW, Jackson JS. Racial/ethnic discrimination and health: findings from community studies. Am J Public Health. 2003;93:200-8.

55. Williams DR, Yu Y, Jackson JS, Anderson NB. Racial differences in physical and mental health: socioeconomic status, stress, and discrimination. J Health Psychol. 1997;2:335-51. doi:10.1177/ 135910539700200305.

56. Yoo H, Gee G, Takeuchi D. Discrimination and health among Asian American immigrants: disentangling racial from language discrimination. Soc Sci Med. 2009;68(4):726-32. 